\title{
ENFRENTAMENTO DE PROBLEMAS CONCEITUAIS E DE PLANEJAMENTO AO FINAL DA FORMAÇÃO INICIAL*
}

\section{Facing conceptual and planning problems at the end of initial training}

\author{
Sandro Rogério Vargas Ustra ${ }^{1}$ \\ Claudio Luiz Hernandes ${ }^{2}$
}

\begin{abstract}
Resumo: Apresenta-se uma reflexão sobre o processo de enfrentamento de problemas por futuros professores de Física, no período de estágio supervisionado, a partir de modelos construídos numa pesquisa desenvolvida junto a um grupo de professores em formação continuada. A atuação em grupo também foi preferida pelos estagiários para enfrentar problemas relacionados ao planejamento didático e de ordem conceitual. Os professores, quanto aos problemas conceituais, são mais persistentes ao tentarem resolvê-los, o que está associado ao contexto próprio de sua atuação, distinto daquele dos estagiários. O engajamento dos estagiários no enfrentamento de problemas genuínos associados ao planejamento, à semelhança do que ocorreu no grupo de professores, representou um processo importante para a construção do conhecimento profissional, individual e coletivo. As contribuições do trabalho apontam para o fortalecimento das disciplinas de práticas de ensino na formação inicial e sugerem atividades para a formação continuada.
\end{abstract}

Palavras-chave: Formação docente. Complexidade na sala de aula. Desenvolvimento profissional, Enfrentamento de problemas. Planejamento didático.

\begin{abstract}
This article presents a discussion about the process of facing problems experienced by future teachers of physics in the period of supervised probation, from models found among a group of teachers in continuing training. The action group was also in method most used by the trainees to face problems related to didactic planning and conceptual order. Teachers when confronted with conceptual problems are more persistent when trying to solve them than the trainees; this is linked to the context itself. The engagement of trainees in facing genuine problems related to planning, as it occurred in the group of teachers, represented an important process for the construction of professional knowledge, individually and collectively. The contributions of this work strengthen the disciplines of teaching practices in initial education and suggest activities for the continuing training of teachers.
\end{abstract}

Keywords: Teachers' education. Classroom complexity. Professional development. Facing problems. Didactic planning.

\footnotetext{
* Artigo elaborado com base em trabalho apresentado no XI Encontro de Pesquisa em Ensino de Física, promovido pela Sociedade Brasileira de Física em 2008.

${ }^{1}$ Licenciado em Física, doutor em Educação. Docente, Departamento de Ciências Exatas e da Terra - DCET, Universidade Regional Integrada do Alto Uruguai e das Missões (URI). Santiago, RS, Brasil.

<srvustra@hotmail.com>

${ }^{2}$ Licenciado em Física, mestre em Educação. Docente, DCET, URI. Santiago, RS, Brasil.<clhernandes@yahoo.com.br>

${ }^{1}$ Av. Bonotto Sobrinho, s/n

Santiago, RS

97.700-000 


\section{Introdução}

Este trabalho consiste numa reflexão sobre o processo de enfrentamento de problemas no término da formação inicial (período de estágio) de professores de física, utilizando modelos encontrados junto a um grupo de professores (também de física) em formação continuada.

Os problemas enfrentados referem-se a questões conceituais de física e a situações relacionadas à tarefa de planejar a intervenção em sala de aula. Os dados utilizados (significados construídos) são oriundos de trabalhos anteriores desenvolvidos pelos autores (ANIBLE; HERNANDES, 2006; USTRA, 2006; HERNANDES; BRAUNER, 2005). Uma descrição mais detalhada dos procedimentos metodológicos empregados está disponível nas referências citadas.

Os modelos para se compreender o processo de enfrentamento de problemas, objeto de análise neste momento, foram construídos a partir do acompanhamento das atividades de um grupo de professores de física em formação continuada e comprometido com a construção e implementação de planejamentos didáticos.

A investigação, no âmbito da formação inicial, envolveu dez alunos estagiários durante o desenvolvimento das disciplinas de Prática de Ensino de Física I (preparativos para o estágio supervisionado) e de Prática de Ensino de Física II (estágio supervisionado - docência na escola), nos períodos letivos de 2004 ( $2^{\circ}$ semestre) a 2006 ( $1^{\circ}$ semestre). As informações, neste espaço, foram obtidas a partir de entrevistas semiestruturadas (formais e informais) e observações sistemáticas desenvolvidas com os estagiários.

Neste artigo, privilegiamos um exercício reflexivo sobre estas duas experiências distintas, mas com afinidades teóricas, configurando um esforço de síntese importante para contribuir com análises e novas possibilidades de investigação nos espaços de formação inicial e continuada.

\section{Modelos para o enfrentamento}

De acordo com o trabalho desenvolvido no espaço de formação continuada (USTRA, 2006), a atuação dos professores (no grupo acompanhado), durante o enfrentamento de problemas conceituais, pôde ser compreendida por meio da consideração dos elementos sistematizados na Figura 1.

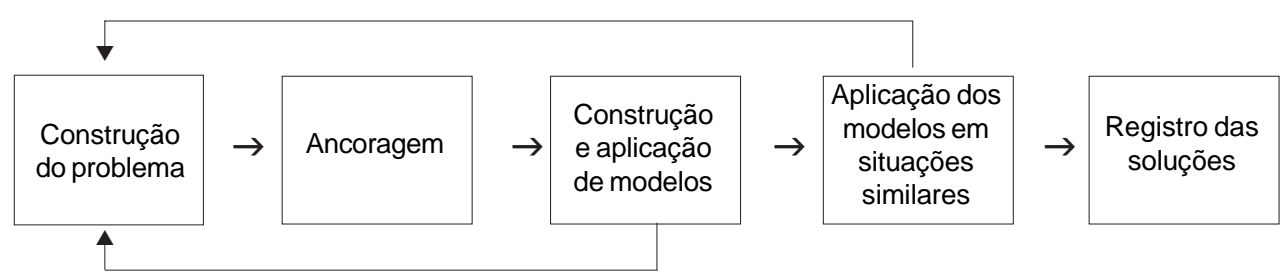

Contexto do trabalho do professor

Figura 1. Enfrentamento de problemas conceituais pelos professores no grupo. 
Sobre os elementos apresentados:

1. Construção do problema: os professores "constroem" o problema identificando as questões problemáticas. Esta construção se dá por meio da perspectiva pessoal de cada um, incluindo, além da dúvida de conteúdo, um teor da importância da questão para suas práticas.

2. Ancoragem no familiar: As estratégias de enfrentamento baseiam-se em situações ou aspectos familiares, que os professores já estão habituados a utilizar ou confiam.

3. Estabelecimento de modelos aceitos pelo grupo e tentativa de aplicação no problema (questão) inicial: As soluções propostas, através de modelos, devem corresponder às situações observadas empiricamente ou previstas nos livros consultados. Muitas vezes, alguns problemas são rediscutidos e suas soluções são trocadas, em função de não se ajustarem a algum aspecto novo.

4. Aplicação das soluções a outros problemas similares: As soluções encontradas para um determinado problema podem ser propostas a problemas similares.

5. Registro do processo e das soluções encontradas: Em geral, os próprios professores fazem os registros dos encaminhamentos e das soluções dadas aos principais problemas conceituais. Entretanto, estes registros nem sempre são sistemáticos e organizados, ocasionando, muitas vezes, dificuldades na compreensão de novos problemas ou detalhes já discutidos ou resolvidos.

Ao resolverem problemas conceituais, os professores constituíam um conhecimento de caso (relacionado à física) que lhes permitia fortalecer o processo de ancoragem, onde intervinham relações de similaridade (que possibilitavam verificar analogias) entre os problemas considerados. Este processo de ancoragem ajudou os professores, no grupo, a fortalecerem seu conhecimento conceitual da disciplina.

Entretanto, é necessário considerar que, na formação continuada e, sobretudo no caso acompanhado, o enfrentamento dos problemas conceituais assume um grau de importância bastante elevado. Não se trata apenas de garantir a formação de membros da comunidade científica (KUHN, 1978), mas a formação de professores engajados num processo de desenvolvimento profissional, comprometidos com a aprendizagem de seus alunos.

Os professores não enfrentavam as questões problemáticas por simples "curiosidade", "espírito investigativo", "vontade de aprender"; mas por necessidades reais advindas de seu vínculo com a sala de aula. Inicialmente, este vínculo foi determinante na construção do problema; apenas depois é que ocorreu um distanciamento deste contexto de sala de aula. Desta forma, no trabalho do grupo, os problemas foram ressignificados no contexto de atuação docente, o qual constitui o $6^{\circ}$ elemento do esquema da Figura 1.

Neste distanciamento em relação ao ambiente de sala de aula e aos alunos, a questão do conhecimento em física torna-se tão ou mais importante que a própria prática. É, sobretudo, nesta fase de construção do problema que os professores legitimam os problemas como seus, engajando-se, efetivamente, no processo de enfrentamento.

Assim, tratava-se de considerar professores que assumiram o aprendizado do conteúdo de física como necessidade própria de cada um, no âmbito do grupo. O ponto de partida constituiu-se dos problemas conceituais reais que cada um enfrentava em seu contexto de trabalho.

A segurança no conhecimento conceitual e a incorporação das soluções (mesmo que provisórias) das questões conceituais problemáticas ao repertório dos professores, obtidas no 
grupo, durante o estudo do conteúdo, refletiram-se diretamente no início da atividade de planejamento. Esta atividade conformou-se, primeiramente, por meio da organização de materiais e conteúdos pelos professores, para, depois, contemplar a perspectiva do aluno, que ocorreu, sobretudo, na discussão das "intenções" relacionadas aos planejamentos.

O momento do planejamento, também apresentado no trabalho referido (USTRA, 2006), pôde ser resumido conforme o esquema da Figura 2.

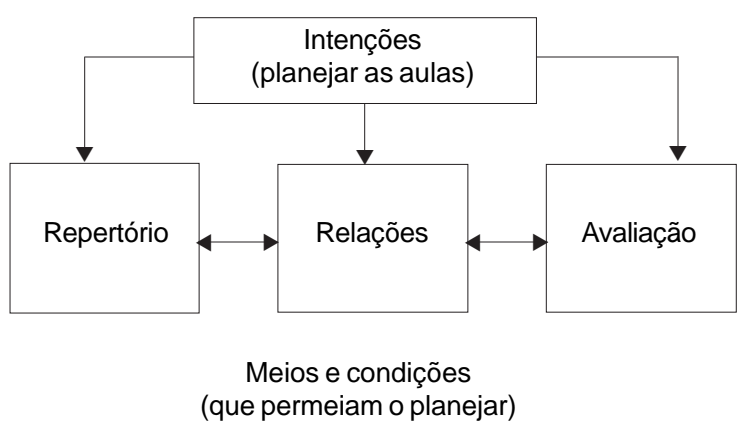

Figura 2. Elementos da construção dos planejamentos no grupo.

Neste modelo estão organizados os elementos identificados durante o acompanhamento da atividade de planejamento no grupo:

1. Repertório - de atividades, primeiramente, mas também de exemplos, imagens, compreensões e ações (SCHÖN, 2000), dentre as quais os professores fazem escolhas, nem sempre conscientes de suas razões.

2. Intenções - que levam a escolha de certos elementos do repertório, nem sempre criteriosas ou explicitadas.

3. Relações - que serão construídas entre os elementos escolhidos do repertório, as quais levam em conta fatores como sensibilidade à ação esperada do aluno e segurança do professor frente ao conteúdo e à sua abordagem.

4. Meios e condições - para desenvolver as relações planejadas, nos quais intervêm aspectos internos e externos à sala de aula.

5. Avaliação - coletiva dos planejamentos, tanto daqueles em construção pelos demais professores do grupo, quanto do desenvolvimento dos próprios planejamentos elaborados.

Estes elementos ganham um significado bem mais amplo no planejamento em grupo, pois, neste caso, estão presentes: a discussão de vários repertórios individuais e suas interrelações; a discussão das intenções, geralmente com justificações que se tornam bastante criteriosas; possibilidades de construção de novas relações entre os elementos previstos nos planejamentos; a previsão e discussão de meios e condições para o desenvolvimento; e, sobre- 
tudo, a avaliação prévia e coletiva do planejamento de cada professor, além da possibilidade de participar da avaliação do planejamento de outro professor, muitas vezes com elementos semelhantes ao seu próprio planejamento (que ainda não foi para a sala de aula).

Este último elemento, da avaliação, representa uma espécie de feedback virtual, onde o professor pode fazer algumas aproximações (considerando, também, a discussão coletiva de previsões dos outros) das situações que poderá enfrentar no desenvolvimento de seu próprio planejamento, por meio do planejamento do outro. E isto apenas é possível no coletivo de professores.

A avaliação dos planejamentos (em construção, desenvolvimento ou já desenvolvidos), considerando a perspectiva da aprendizagem dos alunos, permitiu, aos professores, a revisão e explicitação criteriosa das intenções e das atividades implementadas em sala de aula.

No esquema apresentado, "meios e condições" configuraram-se como um elemento que perpassou toda a ação de planejar no grupo e que contemplou, também, a perspectiva maior da complexidade, a qual, simultaneamente, apresenta-se em sala de aula e a ultrapassa, requerendo, dos professores, uma postura de enfrentamento de situações mais abrangentes, adversas ao desenvolvimento do planejamento na maioria das vezes.

\section{Nos estágios supervisionados}

No acompanhamento da formação inicial em física (ANIBLE; HERNANDES, 2006; HERNANDES; BRAUNER, 2005), mais especificamente do período de estágio supervisionado, também identificamos situações-problema ligadas ao conteúdo específico e ao ato de planejar as ações didáticas. Deste modo, propomos uma reflexão sobre estas situações à luz dos modelos apresentados anteriormente.As tensões que antecederam a prática pedagógica e foram enfrentadas pelos estagiários passavam pelas orientações emanadas da universidade, definição de escola e turma, rotinas impostas pela escola e pelo professor regente da turma.

Para a definição do espaço, os estagiários levavam em consideração: os conteúdos trabalhados, a localização da escola, referências da turma (se era considerada uma "turma problema" ou não), entre outros elementos. Um critério explícito para escolha era o sentimento de segurança conceitual, avaliado pelo próprio estagiário, em relação aos conteúdos específicos da série em que se encontrava a turma.

Definida a turma para estágio, na maioria dos casos, o professor regente era quem estabelecia os tópicos de ensino que o estagiário iria desenvolver numa carga horária delimitada. Muitas vezes, a orientação desse professor implicava uma sensível redução da autonomia para escolha de materiais didáticos, inclusive dos tipos de abordagens metodológicas utilizadas. Espaços negociados e delimitados, iniciava-se, então, o trabalho de planejamento das aulas.

O planejamento das aulas, pelos estagiários acompanhados, consistia numa ação carregada de preocupações, da seguinte ordem: "Qual a melhor maneira de encaminhar os conteúdos e discussões? Será que eu estarei substituindo o professor titular da disciplina a altura? E os alunos, será que vão fazer muitas perguntas? E se eu não souber responder?”

O estagiário possuía várias diretrizes que o orientavam na construção do seu planejamento: utilização de momentos pedagógicos - problematização inicial, organização do conhecimento e aplicação do conhecimento segundo proposta de Delizoicov e Angotti (1991); de- 
senvolvimento de atividades experimentais; utilização de textos de divulgação científica; e uso de analogias e metáforas.

As maiores dificuldades prévias, na visão dos próprios estagiários, eram: "medo" da disciplina de física (linguagem de "códigos e símbolos" empregada); limitações para interpretar as questões e situações relativas ao conteúdo específico; aulas apenas de "quadro e giz"; conteúdos desvinculados da realidade; falta de "bons professores" na escola; carência de conhecimento básico e de interesse, pelos alunos; e receios na elaboração dos relatórios de estágio.

As entrevistas desenvolvidas com os estagiários indicaram que os mesmos, durante o período de planejamento, demonstram uma preocupação centrada na sua própria ação: o foco de sua atenção é o próprio conhecimento (acerca do conteúdo, principalmente) e como será desenvolvido o planejado. Seus alunos representam uma preocupação menor, geralmente associada à sua interferência em relação ao planejado.

As respostas obtidas ao questionamento acerca das possíveis influências no modo de desenvolver o planejamento foram indicativas desta focalização na própria atuação. As influências são atribuídas sobretudo:

- Ao modo de distribuir o conteúdo e de exemplificar com o cotidiano;

- Ao comportamento da turma, seu modo de agir frente à física, seu poder de raciocínio e grau de "aproveitamento" de experiências extraclasse;

. À "calma" e "compreensão" do próprio estagiário;

. Às aplicações do conhecimento;

- Aos experimentos planejados.

Em relação aos problemas de ordem conceitual, os estagiários demonstraram a sensação de que o nível de seu conhecimento talvez não fosse suficiente para tratar as questões iniciais levantadas pelos seus alunos, bem como certo receio de outras que poderiam surgir durante o desenvolvimento do planejamento.

Assim, a experiência em sala de aula remeteu à necessidade de aprofundamento dos estudos. Neste contexto, ou eles enfrentavam o desafio ou acabavam abandonando as questões que lhe deram origem. As questões incluídas em seus planejamentos foram as que souberam resolver com facilidade. A maneira encontrada para resolver algumas questões cruciais (comumente propostas pelos professores regentes) implicou, frequentemente, no estudo em grupos, pelos estagiários. Entretanto, houve situações em que a ajuda do orientador do estágio (docente supervisor, da universidade) foi solicitada.

Poucas questões se configuraram como problemas a serem resolvidos pelos estagiários. Destas, pouquíssimas foram inseridas nos planejamentos elaborados. Predominaram, portanto, os exercícios para os quais apresentavam segurança na resolução.

Mesmo as questões problematizadoras não foram propostas para gerar problemas; o objetivo resumiu-se a estabelecer relações entre o conteúdo programático e o cotidiano (que era o dos estagiários, predominantemente).

Nas palavras de um dos estagiários:

'[...] devemos considerar o conbecimento cientifico na elaboração de um planejamento voltado à construção do conbecimento significativo do aluno e, na hora de ensinarmos, devemos sempre considerar o nivel de conbecimento trazido, o meio social onde vive e também a sua motivação em aprender. É preciso ter uma visão 
além da sala de aula para poder trabalhar a disciplina de física, sempre relacionando a fatos ocorridos no cotidiano."

Os planejamentos construídos pelos estagiários foram desenvolvidos em sala de aula de forma a preservar a sequência preestabelecida pelo regente. As principais modificações efetuadas consistiram em acrescentar ou retirar exercícios, conforme o tempo despendido nas atividades implementadas.

Basicamente, as aulas apresentavam três etapas distintas: exposição dos conceitos principais do conteúdo; demonstração de atividades experimentais sobre o tema da aula; e apresentação de exemplos com exercícios corrigidos, predominantemente, pelos próprios estagiários.

Os estagiários manifestavam a crença de que:

[...] uma lousa bem organizada, com sequências bem definidas, material reproduzido distribuído para os alunos e uma fala inclusiva seriam a garantia de uma boa aula e do respeito dos alunos, por ter um "método" bem definido. (ANIBLE; HERNANDES, 2006, p. 9)

Portanto, as aulas fundamentavam-se na ação principal do futuro professor, com pouco espaço destinado para a atuação dos alunos.

Entretanto, durante as reuniões de avaliação dos estágios (foram promovidas duas com a participação de todos), os estagiários manifestaram seu espanto com o contexto da prática de sala de aula e a "interferência" provocada pelos alunos da turma.

Em relação ao contexto da prática, as dificuldades referiam-se a: utilização de recursos didáticos (organização espacial do quadro, utilização de materiais de laboratório, disponibilização de roteiros e apostilas, entre outros), dimensionamento do tempo de aula; organização das atividades didáticas (exercícios, atividades em grupo, leituras).

Uma manifestação é indicativa, neste sentido: "[...] não é fácil... Chegar em uma sala de aula, com tempo cronometrado e tentar fazer um excelente trabalho".

Quanto aos seus alunos, predominava a referência à falta de interesse de muitos. Também se referiam às dificuldades destes na compreensão do conteúdo (sobretudo de interpretação e de fundamentação matemática).

Foram frequentes afirmações, pelos estagiários, do tipo:

"Ao chegar na turma hoje me surpreendi com a agitação da mesma.

A principal dificuldade enfrentada no periodo de hoje foi adequar a aula ao tempo previsto, ou seja, desenvolver o conteúdo proposto a fim de atender aos anseios da turma. [...] A aula terminou antes que começassem a resolvê-los no quadro.

Dei um tempo para eles se acalmarem enquanto distribui a folha com o conteúdo $e$ com o exercício.

Ao que posso entender, a minha dificuldade e da maioria dos alunos é entender a física sem a prática, a física-teoria integrada com a física-prática, facilita o entendimento de todos, pois pode ser mostrada e fundamentada ao mesmo tempo." 
Outra constatação comum foi a dificuldade em planejar, sobretudo de modo individual. Quando os estagiários se reuniam em grupos, a construção dos planejamentos ocorria de forma menos complicada, pois compartilhavam expectativas, ideias, dificuldades e alternativas possíveis.

Em relação às experiências vivenciadas, passaram a perceber que o "domínio de conteúdo" e "de sala de aula" não é algo obtido automaticamente no final de um curso de licenciatura:

'[...] e como iniciantes ainda não temos uma visão clara da realidade escolar, pois a teoria didática e estrutural que vimos enquanto acadêmicos, na maioria dos casos, diverge daquela encontrada na escola; mas esperamos que, ao exercer a profissão não mais como estagiário, vamos adquirindo competências e habilidades necessárias a prática docente (sic)."

Algumas vezes, parecia, aos futuros professores, que o desenvolvimento profissional poderia ser "adquirido" pela repetição:

'[...] a questão da repetição... a gente acaba por aprender, pois até o professor como iniciante tem uma certa dificuldade e um professor que atua há algum tempo... aquilo para ele tá dominado; é natural, por tantas vez̧es estar repetindo (sic)."

Em outros momentos, os estagiários enfatizavam o próprio desenvolvimento tecnológico e científico como um dos motivos determinantes para a formação continuada: "[...] precisamos nos aperfeiçoar a cada dia que passa, pois sabemos que novas descobertas vão acontecendo e, se não nos atualizarmos, ficaremos para trás."

Entretanto, os saberes necessários para a prática docente são muitos, e não existe um modelo pronto para ser seguido; mas, existe, sim, a construção de modelos ao longo de toda a vida, e, para tornar-se professor, é necessário considerar experiências e vivências desde a escolarização inicial.

Nas palavras de um dos futuros professores, cuja entrevista encontra-se num dos trabalhos mencionados (HERNANDES; BRAUNER, 2005, p. 3): "é difícil ser um educador, levar a motivação ao aluno, não apenas transferir conteúdos, mas sim dar significado ao que se ensina".

\section{Considerações finais: articulando contextos distintos}

Em relação ao enfrentamento de problemas conceituais, relacionados à física, diferentemente dos professores do grupo em formação continuada, os estagiários demonstraram um critério de seletividade vinculado a uma estratégia de sobrevivência denominada de adaptação ao contexto (CONTI, 2003). Desta forma, reportavam-se intensamente às experiências curriculares do curso de formação, escolhendo exercícios que lhes garantissem uma resolução segura em sala de aula. 
Apesar de se referirem à importância de se considerar o cotidiano dos alunos, os estagiários evitavam tratar problemas conceituais com eles. A resolução prévia dos exercícios ocorria, frequentemente, em grupos, nos quais discutiam a melhor estratégia para sua reprodução em sala de aula.

Em relação à tarefa de planejamento, o ponto de partida para os futuros professores consistia em organizar os conteúdos, numa estrutura semelhante à usualmente adotada pelos livros didáticos, e imaginar como seriam os alunos e quais aspectos lhes chamariam mais a atenção em sala de aula. Também, neste sentido, os estagiários diferenciavam-se dos professores em exercício, conforme foi relatado. Estas diferenças estão associadas ao contexto próprio de atuação dos professores, distinto daquele dos estagiários.

As dificuldades encontradas no desenvolvimento do planejamento, pelos estagiários, são típicas de: professores iniciantes, indisciplina e falta de motivação dos alunos (mais sérias) - a primeira pela falta de procedimentos estruturados para lidar com a classe, e a segunda advém das diferenças individuais dos alunos. Outras dificuldades também são apontadas pela literatura da área:

[...] as dificuldades de os docentes iniciantes lidarem com: meios audiovisuais, os pais, a comunidade, atividades de avaliação, além de possuírem uma elevada preocupação com a própria competência, centrando mais a atenção em si próprios do que nos alunos. (LONGHINI; HARTWIG, 2007, p. 438)

Esta focalização na própria competência, indicada na citação anterior, também foi destacada na investigação em foco, especialmente durante a elaboração dos planejamentos pelos futuros professores.

A falta de experiência de sala de aula, enquanto professor, implica que a elaboração do planejamento pelos estagiários é, em grande parte, fruto de suas próprias concepções, que minimizam o peso do contexto de sala de aula, embora tenham consciência da "perturbação" provocada pelos alunos, que têm vontades e interesses distintos. Assim, a construção do planejamento das aulas, geralmente, é carregada de crenças e concepções de ensino espontâneas, que foram sendo construídas ao longo de sua escolarização.

O acompanhamento dos estagiários mostrou, entre outros aspectos, que os mesmos têm uma grande expectativa em relação ao estágio supervisionado, ou seja, a passagem da condição de aluno à de professor é carregada de preocupações, sentimentos, imagens, saberes e modelos de ação docentes vivenciados ao longo de sua vivência e, sobretudo, de sua vida escolar.

Em muitas passagens foi possível perceber uma influência significativa dos seus professores da Educação Básica. Nestes, o traço mais destacado foi a sua empatia com a turma. Desta forma, foram comuns asserções do tipo: "Alguns professores deixaram a desejar... não demonstraram muito entusiasmo. (As) explicações eram diretas e objetivas, com aulas tradicionais; mas, mesmo assim, empolgantes".

Os saberes que o estagiário possui para enfrentar a prática pedagógica são: de ordem conceitual (construídos na universidade), experiências vividas (enquanto aluno, principalmente) e os modelos e exemplos do ser e agir de professores, apreendidos durante a sua formação escolar. 
São estes saberes que orientam as relações estabelecidas entre elementos que constituem o repertório do estagiário e que contribuirão na conformação do seu planejamento.

É neste sentido que as práticas educativas, nas disciplinas preparatórias ao estágio, têm sua importância destacada, enquanto espaço e tempo de formação profissional, incidindo como mais um lugar de experiência formativa.

A principal semelhança encontrada nas duas situações consideradas - formação continuada e estágios -, além da possibilidade de podermos compreender ambas com os mesmos modelos propostos (de modo geral), está na forma de enfrentamento dos problemas, a qual se fundamentava na atuação coletiva, sobretudo no momento do planejamento.

As situações problemáticas envolvendo o planejamento (e sua implementação) mostraram a ocorrência de um engajamento dos estagiários no enfrentamento de problemas genuínos, à semelhança do que ocorreu no grupo de professores. Isto representou, portanto, um processo importante para a construção do conhecimento profissional, individual e coletivamente.

Esse conhecimento não é restrito à física escolar, mas relaciona-se a outros saberes curriculares, a saberes didáticos específicos e a saberes da experiência ampliada (que extrapolam os limites da formação escolar), sob a abrangência de saberes mais gerais e organizativos: os saberes metadisciplinares.

Neste sentido, os repertórios, os interesses e os contextos próprios de cada estagiário/professor caracterizam a complexidade do trabalho docente, diferenciando, significativamente, suas formas de enfrentamento dos problemas conceituais. Conhecer estas diferenças é imprescindível para se explorar criteriosamente os limites dos modelos propostos ao enfrentamento, tanto de problemas conceituais, quanto de problemas relacionados ao planejamento.

As disciplinas de Prática de Ensino e Estágio constituem momentos especiais para o processo de formação e de desenvolvimento profissional do professor, pois são estas que estabelecem e/ou intermedeiam mais diretamente a transição do acadêmico da condição de aluno a professor - e, portanto, não podem ser vistas como meras instâncias de treinamento e aplicação prática de metodologias apreendidas previamente. Mas, ao contrário, constituem momentos complexos que mobilizam e colocam sob tensão os saberes, as crenças, as concepções, e os fazeres do professor iniciante, que foram aprendidos durante os vários anos de escolarização e de adaptação com este campo de trabalho.

Esta perspectiva aponta para o fortalecimento das disciplinas de Prática de Ensino e Estágio, especialmente como espaço de (re)construção de saberes relacionados à formação continuada. Espaço este onde o contexto de atuação docente e a coletividade têm posição de destaque, com vistas à conquista da autonomia e ao desenvolvimento profissional de fato. 
Enfrentamento de problemas conceituais ...

\section{Referências}

ANIBLE, C. B.; HERNANDES, C. L. A prática de ensino de física: passagem de aluno a professor. Erechim: Universidade Regional Integrada do Alto Uruguai e das Missões, Pró-Reitoria de Pesquisa, Extensão e Pós-Graduação, 2006. (Relatório de pesquisa).

CONTI, C. L. A. Imagens da profissão docente: um estudo sobre professoras primárias em início de carreira. 2003. 177f. Tese (Doutorado em Educação) - Faculdade de Educação, Universidade Estadual de Campinas, Campinas, 2003.

DELIZOICOV, D.; ANGOTTI, J. P. Metodologia do ensino de ciências. São Paulo: Cortez, 1991.

HERNANDES, C. L.; BRAUNER, O. T. Expectativas de alunos em formação inicial sobre a prática de ensino de física supervisionado. In: SIMPÓSIO NACIONAL DE ENSINO DE FÍSICA, 16., 2005, Rio de Janeiro. Atas... Rio de Janeiro: Sociedade Brasileira de Física, 2005. 1 cd-rom.

KUHN, T.S. A estrutura das revoluções científicas. São Paulo: Perspectiva, 1978.

LONGHINI, M. D.; HARTWIG, D. R. A interação entre os conhecimentos de um professor atuante e de um aspirante como subsídio para a aprendizagem da docência. Ciência \& Educação, Bauru, v. 13, n. 3, p. 435-451, 2007.

SCHÖN, D. Educando o profissional reflexivo: um novo design para o ensino e a aprendizagem. Porto Alegre: Artmed, 2000.

USTRA, S. R.V. Formação continuada de professores de física: enfrentamento de problemas reais. 2006. 141f. Tese (Doutorado em Educação) - Faculdade de Educação, Universidade de São Paulo, São Paulo, 2006.

Artigo recebido em agosto de 2010 e aceito em outubro de 2010. 